\title{
TOPIC: INGUINAL HERNIA - Primary inguinal hernia, state of the art in the different socio economic reality
}

(C) Springer-Verlag 2014

\section{VS:42}

TRANS INGUINAL PRE PERITONEAL PROCEDURE (MINIMALLY OPEN APPROACH) WITH A NEW EXPANDABLE, POLYPROPYLENE MESH, PROSTHESIS

M Soler ${ }^{1}$

'Clinique Saint Jean, Cagnes sur Mer, France

Trans inguinal pre peritoneal procedure(TIPP hernioplasty), represents after the grid iron technique (F. Ugahary), the last evolution of the Minimal Open Pre Peritoneal approach for the treatment of groin hernias.

This Minimal Open Pre Peritoneal (MOPP) approach, allows a minimal access, and a minimal invasive, tension free, and sutureless procedure, with protection for the nerves. The main difficulty of the technique, was to unrolled the prosthesis through a $4 \mathrm{~cm}$ incision. The use of the new semi expandable prosthesis, makes easier the technique and secures the good position of the mesh, especially for the big medial hernia.

The author has used this new self expandable prosthesis (polypropylene mesh with an additional not woven ring).

The movie shows the TIPP technique, and specially, how to unroll, the prosthesis in the preperitoneal space.

The semi rigid border of the prosthesis makes easier how to put the prosthesis in the right position.

After 500 cases, a prospective study, is under way, with no recurrence, and a low rate of chronic pain. 